\title{
Balanced Active and Reactive Control Applied to a Grid Connected Five Level Inverter
}

\author{
Chabakata MAHAMAT \\ University of Tunis El Manar, \\ Faculty of Sciences of Tunis \& \\ ENS of Paris-Saclay \\ Laboratories: SATIE \& LAPER
}

\author{
Mickaël PETIT \\ National Conservatory of Arts and \\ Crafts (Cnam) of Paris, CNRS, \\ Laboratory: SATIE \\ Cachan, France
}

\author{
François COSTA \\ Université Paris Est Créteil \\ ESPE of Créteil, CNRS, \\ Laboratory: SATIE \\ Cachan, France
}

\author{
Rym MAROUANI \\ University of Tunis El Manar \\ Faculty of Sciences of Tunis, Laboratory: LAPER \\ Tunis, Tunisia
}

\author{
Abdelkader MAMI \\ University of Tunis El Manar \\ Faculty of Sciences of Tunis, Laboratory: LAPER \\ Tunis, Tunisia
}

\begin{abstract}
This paper presents a balanced active and reactive power control, using a Phase Locked Loop for synchronization, and applied to a grid connected Five Level Inverter. The energy source of the system can be a photovoltaic generator or a wind turbine. We size the passive elements of the system and explain the value of the system architecture using a Five Level Inverter when compared to a classical grid connected system. We also compare the balanced active and reactive power control to an unbalanced active and reactive power control. The simulation results obtained by using Matlab Simulink and Simpowersystems are presented and discussed in this paper.
\end{abstract}

Keywords-Balanced control; grid connected system; multilevel inverter

\section{INTRODUCTION}

Maximizing the power transfer from the energy source to the electrical grid and optimizing the system dynamics both depend on the used static converter technology and its control algorithms [1]. In grid-connected system, we must use a $L C L$ filter to connect the inverter to the utility grid in order to obtain a good attenuation of high frequency harmonics generated by the inverter [1], [2], [7]. This is the case of [1]-[3], [15], [17] and [18]. However, using a $L C L$-filter requires a sophisticated control, due to the increase in filter order. Insofar as it is no longer possible to control the system using traditional controllers (PI: Proportional Integral), we must use other types of control such as cascade controllers, sliding mode control, fuzzy logic control as in [11], [12] and [16] .

To solve this problem, we propose an architecture of gridconnected system using a Five-Level Inverter $(F L I)$ with an interleaved $L$-filter and controlled by a balancing $P Q$-control. The use of this innovative structure using a FLI in this domain should allow a decrease in filter volume and a gain in system reliability, and in energy quality.
So the objectives of this work are to analyze the gridconnected system using an FLI with an interleaved $L$-filter and to show the value of this architecture compared to the classical grid-connected system. We are particularly interested in balancing control and sizing of this system, in a context of use in Africa where the cost, reliability and energy quality issues of the system should be taken into account. The considered grid is a low voltage grid $(230 \mathrm{~V})$ with a frequency equal to fifty hertz $(50 \mathrm{~Hz})$ but likely to vary, in which a maximum power of five point two kilowatts $(5.2 \mathrm{~kW})$ is injected. Those are the standards of the national electricity company of Chad (SNE: Société Nationale d'Electricité du Tchad).

This work is organized as follows: Section II describes the system under study, Section III presents the FLI principle, Section IV presents the sizing of passive elements, and Section V details the system's modeling and control. Finally, the simulation results and discussion are provided in Section VI.

\section{DESCRIPTION OF THE SYSTEM}

Fig. 1 shows the proposed architecture of the grid connected system and its control.

This system is composed of two parts: a continuous part $(D C)$ and an alternative part $(A C)$. The $D C$ part is the energy source which can be a photovoltaic generator or a wind turbine. The $A C$ part is composed by the FLI, the utility grid and is controlled by a balanced active and reactive power control ( $P Q$ - control). A Phase-Locked Loop ( $P L L)$ is used to synchronize the system with the grid. The balanced $P Q-$ control is composed of two control loops : an external control loop to control the output current in the Park frame and an internal control loop for local balancing of the cell currents which is done in the abc frame. 


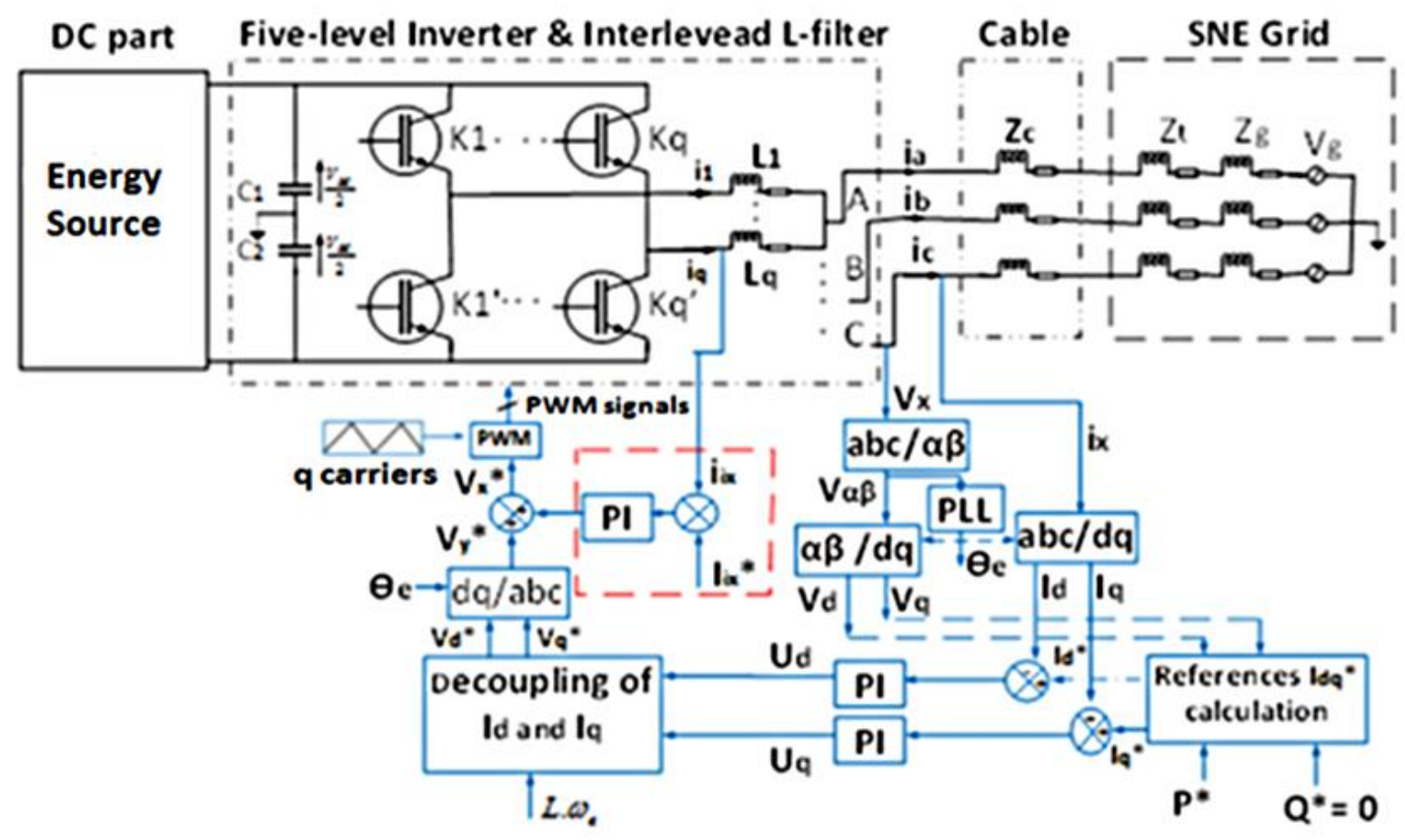

Fig. 1. Grid connected system and its control.

\section{PRINCIPLE OF THE FIVE-LEVEL INVERTER ( $F L I)$}

The simplified diagram of the three-phase $F L I$ is shown in Fig. 2, where $x=a, b, c$ is the phase name of the FLI. It is a parallel structure composed of four interleaved cells.

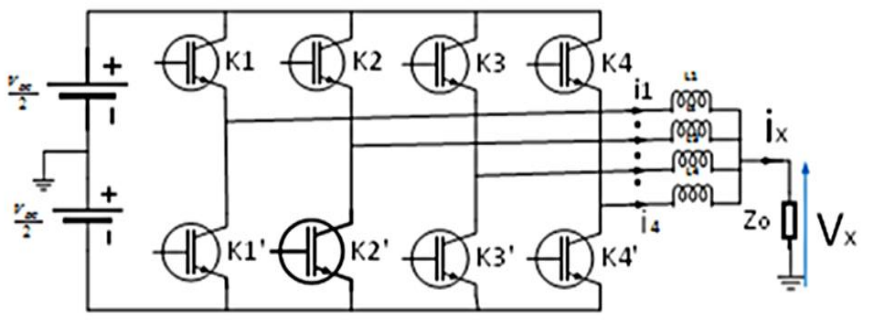

Fig. 2. Simplified diagram of the $\boldsymbol{F} \boldsymbol{L} \boldsymbol{I}$ with L-filter.

As in a classical inverter, the two switches of the same inverter arm are controlled complementarily to avoid short circuits. $K_{i x}=\overline{K_{i x}^{\prime}}$; Where $i=\{1,2,3,4\}$ is the cell number. The $q$ different switching cells are shifted by $\frac{T_{s w}}{q}$ and controlled with the same duty cycle [4], [5]. Where $q=4$ and $T_{s w}$ is the switching period. The three phases of the inverter $(a, b, c)$ are also shifted by $\frac{2 \pi}{3}$.

To simplify, the study of the three-phase inverter can be reduced to a single phase. Fig. 3 shows the output voltage waveforms of the FLI and classical inverter (two-level inverter) for one phase when a $R L$ load is connected (For specifications of the FLI + load, cf. Table 2). (a): Five-level Inverter

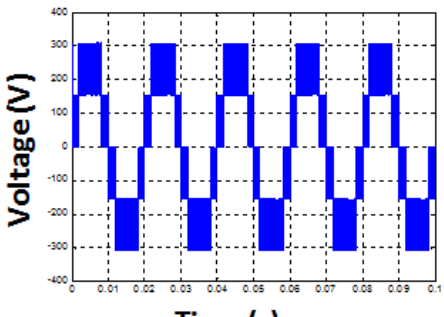

Time (s) (b): Two-level Inverter

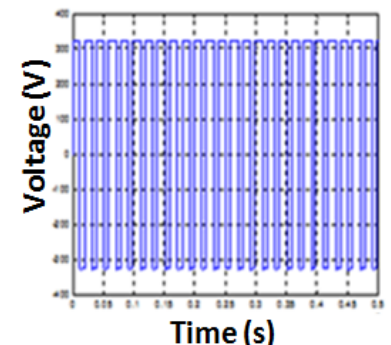

Fig. 3. Waveforms of the voltage vs. time.

Contrary to the waveform of the classical two-level inverter (Fig. 3(b)), the waveform of the FLI is more sinusoidal (Fig. 3(a)). Indeed, this waveform is less rich in harmonics. Moreover, these harmonics are at the apparent frequency which is equal to $q$ times the switching frequency, so they are easy to filter. We can therefore use small caliber passive elements to make the filter.

Furthermore, we can see in Fig. 3(a) that the waveform of the voltage has five voltage levels (two alternating positive + two alternating negative + zero level); hence, the name of the Five Level Inverter $(F L I)$.

\section{MODELING AND SIZING OF THE SYSTEM}

\section{A. Grid modeling}

1) Medium voltage model of the grid

The considered medium voltage line $(15 \mathrm{kV})$ of the $S N E$ grid has a distance $d=9.3 \mathrm{~km}$ and a section $S=185 \mathrm{~mm}^{2}$ 
[8]. So, the resistance of the medium voltage line $\left(R_{1 g}\right)$ is calculated in (1).

$$
R_{1 g}=\frac{\rho \cdot d}{S}
$$

Where $\rho$ is the aluminum resistivity. In the case of Chad which is a hot country with an ambient temperature substantially equal to $T_{a m b}=40^{\circ} \mathrm{C}$ [8], we can consider a maximum temperature equal to $T=75^{\circ} \mathrm{C}$. In addition, this temperature corresponds to the temperature indicated in the datasheet of the considered transformer [9]. In this case, $\rho=3.5929 \cdot 10^{-8} \Omega \cdot \mathrm{m} \quad$ (if $\quad T=T_{0}=20^{\circ} \mathrm{C}, \quad \rho=\rho_{0}=$ $\left.2.941 \cdot 10^{-8} \Omega \cdot \mathrm{m}\right)$ and $R_{1 g}=1.8 \Omega$.

The linear reactance is equal to $X_{l}=0.4 \Omega / \mathrm{km}$ [8]. So the grid medium voltage line inductance is given in (2).

$$
L_{1 g}=\frac{X_{l} \cdot d}{\omega}
$$

Where $\omega$ is the grid pulsation $(\omega=2 \pi f)$. For $=50 \mathrm{~Hz}$, we obtain $L_{1 g}=11.8 \mathrm{mH}$.

2) Low voltage model of the grid

To switch from the medium voltage model to the low voltage model, we use the transformer model seen Fig. 4.

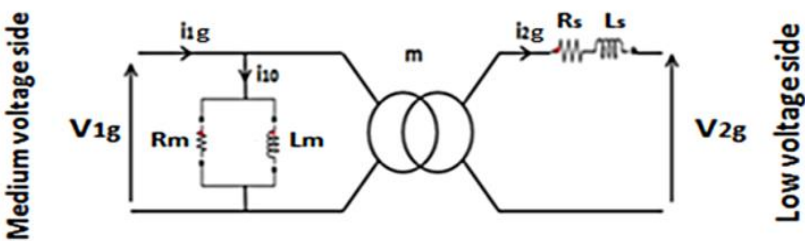

Fig. 4. Simplified transformer model.

By neglecting the losses in the transformer, we can write the power conservation relation in (3).

$$
\mathrm{V}_{1 \mathrm{~g}} \cdot \mathrm{i}_{1 \mathrm{~g}}=\mathrm{V}_{2 \mathrm{~g}} \cdot \mathrm{i}_{2 \mathrm{~g}}
$$

With $\mathrm{V}_{1 \mathrm{~g}}=\mathrm{Z}_{1 \mathrm{~g}} \cdot \mathrm{i}_{1 \mathrm{~g}}, \mathrm{~V}_{2 \mathrm{~g}}=\mathrm{Z}_{2 \mathrm{~g}} \cdot \mathrm{i}_{2 \mathrm{~g}}$ and using (3), we can write (4).

$$
\mathrm{Z}_{2 \mathrm{~g}}=\mathrm{Z}_{1 \mathrm{~g}} \cdot\left(\frac{i_{1 g}}{i_{2 g}}\right)^{2}
$$

On the other hand,

$$
m=\frac{V_{2 g}}{V_{1 g}}=\frac{i_{1 g}}{i_{2 g}}
$$

So $\quad i_{1 g}=m \cdot i_{2 g}$

Using (6), (4) becomes (7).

$$
\mathrm{Z}_{2 \mathrm{~g}}=\mathrm{m}^{2} \cdot \mathrm{Z}_{1 \mathrm{~g}}
$$

Therefore,

$$
\left\{\begin{array}{l}
R_{2 g}=m^{2} \cdot R_{1 g} \\
L_{2 g}=m^{2} \cdot L_{1 g}
\end{array}\right.
$$

Where,
$\mathrm{V}_{1 \mathrm{~g}}$ and $\mathrm{V}_{2 \mathrm{~g}}$ are the medium and low grid line-to-phase voltages respectively;

$i_{1 g}$ and $i_{2 g}$ are the medium voltage side and low voltage side grid currents;

$\mathrm{Z}_{1 \mathrm{~g}}$ and $\mathrm{Z}_{2 \mathrm{~g}}$ are the medium voltage side and low voltage side grid impedances ;

$\mathrm{R}_{1 \mathrm{~g}}$ and $\mathrm{R}_{2 \mathrm{~g}}$ are the medium voltage side and low voltage side grid resistances;

$\mathrm{L}_{1 \mathrm{~g}}$ and $\mathrm{L}_{2 \mathrm{~g}}$ are the medium voltage side and low voltage side grid inductances;

And $\mathrm{m}$ is the voltage ratio.

Note: $R_{1 g}, L_{1 g}, R_{2 g}$ and $L_{2 g}$ are not represented in Fig. 4. Only the internal elements $\left(\mathrm{R}_{\mathrm{m}}, \mathrm{L}_{\mathrm{m}}, \mathrm{R}_{\mathrm{s}}, \mathrm{L}_{\mathrm{s}}\right)$ of the transformer are presented in Fig. 4. The line capacitor is neglected here, so the grid impedance is only composed of its resistance and inductance.

To simplify, we set: $\mathrm{R}_{2 \mathrm{~g}}=\mathrm{R}_{\mathrm{g}}, \mathrm{L}_{2 \mathrm{~g}}=\mathrm{L}_{\mathrm{g}}$ and $\mathrm{Z}_{2 \mathrm{~g}}=\mathrm{Z}_{\mathrm{g}}$.

The transformer line-to-phase voltages are: $\mathrm{U}_{1}=15 \mathrm{kV}$ and $\mathrm{U}_{2}=400 \mathrm{~V}[8]$.

So, $V_{1 \mathrm{~g}}=\frac{\mathrm{U}_{1}}{\sqrt{3}}=8.66 \mathrm{kV}, \mathrm{V}_{2 \mathrm{~g}}=\frac{\mathrm{U}_{2}}{\sqrt{3}}=230 \mathrm{~V}$ and $m=$ 0.0267 .

Thus, using (8), we obtain the grid impedance parameters of the low voltage model: $\mathrm{R}_{\mathrm{g}}=1.3 \mathrm{~m} \Omega$ and $\mathrm{L}_{\mathrm{g}}=8.4 \mu \mathrm{H}$.

So the module of the grid impedance is given in (9).

$$
Z_{g}=\sqrt{\mathrm{R}_{\mathrm{g}}{ }^{2}+\left(\mathrm{L}_{\mathrm{g}} \cdot \omega\right)^{2}}
$$

Where $\omega=2 \pi f$ is the grid pulsation ( $f$ is the grid frequency).

For $=50 \mathrm{~Hz}$, we obtain $Z_{g} \approx R_{g}=3 \mathrm{~m} \Omega$.

\section{$B$. Impedance of the transformer}

The model of the considered transformer is shown in Fig. 4. Some characteristics of this transformer are given in Table 1 [9].

TABLE I. CHARACTERISTICS OF THE TRANSFORMER

\begin{tabular}{|c|l|c|c|}
\hline Symbol & Parameter & Value & Unit \\
\hline $\mathrm{S}_{\mathrm{n}}$ & Rated power & 250 & $\mathrm{kVA}$ \\
\hline $\mathrm{U}_{1}$ & Primary phase-to-phase rated voltage & 15 & $\mathrm{kV}$ \\
\hline $\mathrm{V}_{1}$ & Primary line-to-phase rated voltage & 8.66 & $\mathrm{kV}$ \\
\hline $\mathrm{U}_{20}$ & $\begin{array}{l}\text { Phase-to-phase open circuit secondary } \\
\text { voltage }\end{array}$ & 410 & $\mathrm{~V}$ \\
\hline $\mathrm{V}_{20}$ & $\begin{array}{l}\text { Line-to-phase open circuit secondary } \\
\text { voltage }\end{array}$ & 237 & $\mathrm{~V}$ \\
\hline $\mathrm{u}_{\mathrm{cc}}$ & Short circuit voltage & 4 & $\%$ \\
\hline $\mathrm{I}_{10}$ & Open circuit current & 0.5 & $\%$ \\
\hline $\mathrm{P}_{\mathrm{j}}$ & Losses due to load at $75^{\circ} \mathrm{C}$ & 3250 & $\mathrm{~W}$ \\
\hline $\mathrm{P}_{\mathrm{f}}$ & Open circuit losses & 300 & $\mathrm{~W}$ \\
\hline
\end{tabular}


1) Open circuit test and magnetic elements calculation

The magnetic elements $R_{m}$ and $L_{m}$ of the transformer are calculated by the open circuit test as indicated in (10) and (12).

$$
\begin{gathered}
R_{m}=\frac{V_{1}{ }^{2}}{P_{10}} \\
X_{m}=\frac{V_{1}{ }^{2}}{Q_{10}} \\
L_{m}=\frac{X_{m}}{\omega}
\end{gathered}
$$

Where: $R_{m}$ is the magnetic resistance; $X_{m}$ is the magnetic reactance; $P_{10}$ is the active iron losses; $Q_{10}$ is the reactive iron losses and $L_{m}$ is the magnetic inductance.

The active and reactive iron losses are calculated as follows:

$$
\begin{aligned}
S_{10} & =V_{1} \cdot I_{10} \\
I_{10} & =0.5 \% \cdot I_{1 n} \\
I_{1 n} & =\frac{S_{n}}{3 \cdot V_{1}}
\end{aligned}
$$

On the other hand, characteristics of the Table 1 are given in the case of a three-phase system. For the active iron losses of one phase $P_{10}$, we can consider the open circuit losses $\left(P_{f}\right)$ divided by three as shown in (16).

$$
P_{10}=\frac{P_{f}}{3}
$$

So the reactive iron losses are calculated in (17).

$$
Q_{10}=\sqrt{S_{10}^{2}-P_{10}^{2}}
$$

By injecting (16) in (10), (17) in (11) and using Table 1, we obtain: $R_{m}=750 \mathrm{k} \Omega$ and $X_{m}=1.854 \cdot 10^{5} \Omega$. Finally, using (12) we obtain $L_{m}=590.208 \mathrm{H}$.

2) Short circuit test and serial elements calculation

The serial resistance $R_{S}$ and inductance $L_{s}$ of the transformer are calculated by the short circuit test. The formula of the serial resistance is given in (18).

$$
\mathrm{R}_{\mathrm{s}}=\frac{\mathrm{P}_{\mathrm{j}}}{3 \cdot \mathrm{I}_{2 \mathrm{n}}{ }^{2}}
$$

Where $\mathrm{I}_{2 \mathrm{n}}$ is the rated secondary current.

$$
I_{2 n}=\frac{S_{n}}{3 \cdot V_{20}}
$$

By (18) and (19) and using table $I$, we obtain $R_{s}=$ $8.8 \mathrm{~m} \Omega$.

The mainly parameters which allow to calculate the serial inductance of the transformer $L_{s}$ are the following:

$$
\begin{gathered}
V_{2 c c}=\frac{u_{c c}}{100} \cdot m \cdot V_{1} \\
S_{c c}=V_{2 c c} \cdot I_{2 n}
\end{gathered}
$$

For the active short circuit losses of one phase $P_{c c}$, we can consider the losses due to load $P_{j}$ divided by three as shown in (22). Because the parameters of Table 1 are given in the case of a three-phase system.

$$
\begin{aligned}
P_{c c} & =\frac{P_{j}}{3} \\
Q_{c c} & =\sqrt{{S_{c c}}^{2}-P_{c c}{ }^{2}} \\
X_{S} & =\frac{Q_{c c}}{I_{2 n}{ }^{2}} \\
L_{s} & =\frac{X_{S}}{\omega}
\end{aligned}
$$

Where: $V_{2 c c}$ is the secondary short circuit voltage; $S_{c c}$ is the apparent short circuit losses; $P_{c c}$ is the active short circuit losses; $Q_{c c}$ is the reactive short circuit losses and $X_{S}$ is the reactance of the transformer. $81 \mu \mathrm{H}$.

By considering the above parameters, we obtain $L_{s}=$

Note: We can neglect the magnetic resistance $R_{m}$ and inductance $\mathrm{L}_{\mathrm{m}}$ of the transformer because they have very high values and are connected in parallel (cf. Fig. 4). Thus the internal resistance and inductance of the transformer are equal to the serial resistance and the inductance: $\mathrm{L}_{t}=\mathrm{L}_{\mathrm{s}}$ and $R_{t}=R_{s}$. So the module of the transformer's impedance is given in (26).

$$
Z_{t}=\sqrt{\mathrm{R}_{\mathrm{t}}^{2}+\left(\mathrm{L}_{\mathrm{t}} \cdot \omega\right)^{2}}
$$

For $=50 \mathrm{~Hz}$, we obtain $Z_{t}=27 \mathrm{~m} \Omega$.

\section{Impedance of the Cable}

We consider that the distance between the common connection point of the grid and our installation is equal to $d_{1}=200 \mathrm{~m}$. For this short distance, the capacitor of the cable can be neglected and the model of the cable is only composed of a resistance and an inductance. In addition, a three-phase aluminum cable with a section equal to $S=6 \mathrm{~mm}^{2}$ is selected.

The formula of the cable resistance $R_{c}$ is indicated in (27).

$$
R_{c}=\rho \frac{d_{1}}{S}
$$

Where $\rho$ is the aluminum resistivity ( $\rho=3.5929$. $10^{-8} \Omega \cdot \mathrm{m}$ at $\left.T=75^{\circ} \mathrm{C}\right)$. So we obtain $R_{c}=1.2 \Omega$.

And the formula of the cable inductance $L_{c}$ is given in (28).

$$
L_{c}=\frac{X_{C}}{\omega}
$$

Where $X_{c}$ is the reactance of the cable.

$$
X_{c}=X_{l} \cdot d_{1}
$$

Where $X_{l}$ is the linear reactance of the cable $\left(X_{l}=\right.$ $0.08 \mathrm{~m} \Omega / \mathrm{m}$ ) [8]. By injecting (29) in (28), we obtain $L_{c}=$ $51 \mu \mathrm{H}$. So the impedance of the cable is given in (30).

$$
Z_{c}=\sqrt{\mathrm{R}_{\mathrm{c}}{ }^{2}+\left(\mathrm{L}_{\mathrm{c}} \cdot \omega\right)^{2}}
$$

For $\mathrm{f}=50 \mathrm{~Hz}$, we obtain $Z_{c} \approx R_{c}=1.2 \Omega$.

\section{The Interleaved Inductance (Filter Inductance)}

The four inductances of the interleaved $L$ - filter are identical. The value of these inductances is selected to obtain a 
current harmonic distortion THD of less than five percent (THD $<5 \%$ ) in order to respect the connection standard IEEE 1547 [10]. In addition, nowadays there are photovoltaic inverters on the market with a THD lower than or equal to $3 \%$. Therefore, we are focusing on those existing solutions. Fig. 5 shows the $T H D$ of current versus (vs) inductance.

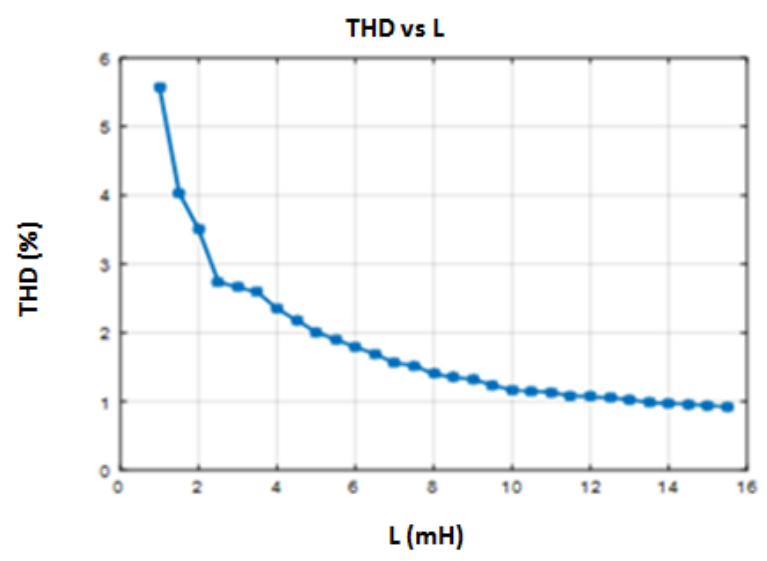

Fig. 5. Selection of the interleaved filter inductance.

We can see in Fig. 5 that for $L=2.5 \mathrm{mH}, T H D<3 \%$, so this inductance value will be selected. Therefore, we use four identical inductances to make the interleaved $L$ - filter $\left(L_{1}=\right.$ $L_{2}=L_{3}=L_{4}=L_{f}=2.5 \mathrm{mH}$ ).

The passive elements of our system are summarized in Table 2. To compare filter volumes, the same inductances values are considered both in the classical inverter and in the FLI.

TABLE II. SPECIFICATIONS OF THE PASSIVE ElEMENTS

\begin{tabular}{|c|c|c|c|c|}
\hline \multirow{2}{*}{ Symbol } & \multirow{2}{*}{ Parameter } & \multicolumn{2}{|l|}{ Value } & \multirow{2}{*}{ Unit } \\
\hline & & $\begin{array}{l}\text { classical } \\
\text { inverter }\end{array}$ & $\begin{array}{l}F L I \\
(q=4)\end{array}$ & \\
\hline$P_{\max }$ & Maximum power & 5.2 & 5.2 & $\mathrm{~kW}$ \\
\hline$V_{D C}$ & DC bus voltage & 700 & 700 & $\mathrm{~V}$ \\
\hline$V_{g}$ & Grid RMS voltage & 230 & 230 & $\mathrm{~V}$ \\
\hline $\mathrm{L}_{\mathrm{g}}$ & Grid side inductance & 8.4 & 8.4 & $\mu \mathrm{H}$ \\
\hline $\mathrm{L}_{\mathrm{t}}$ & Transformer inductance & 81 & 81 & $\mu \mathrm{H}$ \\
\hline $\mathrm{L}_{\mathrm{c}}$ & Cable inductance & 51 & 51 & $\mu \mathrm{H}$ \\
\hline $\mathrm{L}_{\mathrm{f}}$ & Filter inductance & 2.5 & 2.5 & $\mathrm{mH}$ \\
\hline $\mathrm{R}_{\mathrm{f}}$ & Binding filter resistance & 0.5 & 0.5 & $\Omega$ \\
\hline $\mathrm{R}_{\mathrm{c}}$ & Cable resistance & 1.3 & 1.3 & $\Omega$ \\
\hline $\mathrm{R}_{\mathrm{t}}$ & Transformer resistance & 8.8 & 8.8 & $\mathrm{~m} \Omega$ \\
\hline $\mathrm{R}_{\mathrm{g}}$ & Grid side resistance & 1.3 & 1.3 & $\mathrm{~m} \Omega$ \\
\hline $\mathrm{f}_{\mathrm{sw}}$ & Switching frequency & 20 & 20 & $\mathrm{kHz}$ \\
\hline $\mathrm{f}$ & Grid frequency & 50 & 50 & $\mathrm{~Hz}$ \\
\hline $\mathrm{I}_{\mathrm{O} \_\max }$ & Maximum output current & 11.28 & 10.67 & $\mathrm{~A}$ \\
\hline $\mathrm{I}_{\mathrm{L}_{-} \max }$ & Maximum cell current & 11.28 & 3 & A \\
\hline$\Delta \mathrm{I}_{\text {cell }}$ & Cell current ripple & 0.62 & 0.3 & $\mathrm{~A}$ \\
\hline$\Delta \mathrm{I}_{\text {o_max }}$ & Output current ripple & 0.62 & 0.01 & $\mathrm{~A}$ \\
\hline
\end{tabular}

Note: The maximum amplitude of output current shown in this table takes into account the current ripple. Its fundamental value is equal to : $I_{\max }=10.66 \mathrm{~A}$.

Using Table 2, we calculate and compare the volumes of passive elements as follows [7], [13]:

* In general:

- Energy:

$$
W=\frac{1}{2} L I_{L_{-}} \max ^{2}
$$

- Volume:

$$
V_{o l} \propto W^{3 / 4}
$$

$V o l \propto \frac{1}{2} L^{3 / 4} I_{L_{-} \max }{ }^{3 / 2}$

So,

* Three-phase classical inverter $\left(I_{L_{-} \max }=I_{O_{-} \max }\right)$ :

$\operatorname{Vol}_{1} \propto 3 \cdot \frac{1}{2} \cdot L_{f}^{3 / 4} \cdot I_{o_{-} \max }^{3 / 2}$

* Three-phase FLI (q=4):

$\mathrm{Vol}_{2} \propto 3 q \cdot \frac{1}{2} \cdot L_{f}{ }^{3 / 4} \cdot I_{L_{-} \max }^{3 / 2}$

By (4) and (5), the volume ratio is follows:

$$
\lambda=\frac{V_{o l 2}}{V_{o l 1}}=\frac{q^{3 / 4} \cdot I_{L \_} \max ^{3 / 2}}{I_{O_{-}} \max ^{3 / 2}}=0.388
$$

Note: $\lambda<1 \Rightarrow \operatorname{Vol}_{2}<\operatorname{Vol}_{1}$, so the overall volume is reduced in the case of FLI although many components are required.

\section{MODELING AND CONTROL OF THE SYSTEM}

\section{A. Output Current Control (External Loop)}

By considering the internal resistance of our system's components (filter, cable, transformer and grid), the simplified diagram of the grid-connected FLI is shown in Fig. 6.

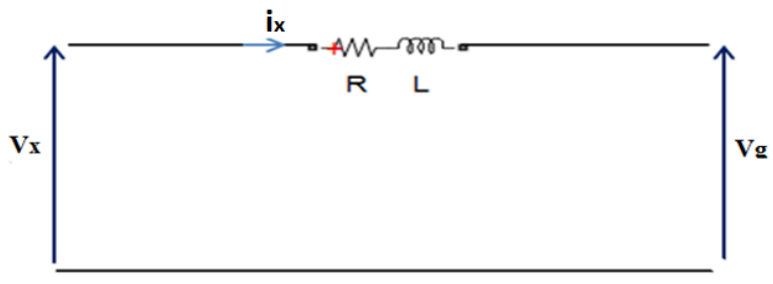

Fig. 6. Simplified connection diagram to the grid [7].

Mathematical models of Fig. 6 are the following:

- In the $a b c$ frame:

$$
V_{x}=L \frac{d i_{x}}{d t}+R i_{x}+V_{g}
$$

Where $V_{x}, V_{g}$ and $i_{x}$ are the inverter voltage, the grid voltage and the grid current respectively. $L$ is the total inductance $\left(L=L_{f}+L_{c}+L_{t}+L_{g}\right)$ whereas $R$ is the total resistance $\left(R=R_{f}+R_{c}+R_{t}+R_{g}\right)$. 
- In the Park frame:

$\left\{\begin{array}{c}L \frac{d I_{d}}{d t}=-R I_{d}+L \omega I_{q}+V_{d}-V_{d g} \\ L \frac{d I_{q}}{d t}=-R I_{q}-L \omega I_{d}+V_{q}-V_{q g}\end{array}\right.$

$V_{d}, V_{d g}$ and $I_{d}$ are the $d$-axis inverter voltage, grid voltage and grid current respectively whereas $V_{q}, V_{q g}$ and $I_{q}$ are the $q$ axis components; $\omega$ is the pulsation $(\omega=2 \pi f)$.

\section{B. Transfer Function of the Filter}

In equation (38), we set [7]:

$$
\left\{\begin{array}{l}
U_{d}=L \omega I_{q}+V_{d}-V_{d g} \\
U_{q}=-L \omega I_{d}+V_{q}-V_{q g}
\end{array}\right.
$$

Using the Laplace transform we obtain:

$$
\left\{\begin{array}{l}
H_{d}(s)=\frac{I_{d}(s)}{U_{d}(s)}=\frac{1}{L s+R} \\
H_{q}(s)=\frac{I_{q}(s)}{U_{q}(s)}=\frac{1}{L s+R}
\end{array}\right.
$$

The transfer function of the $P I$ controller is given in (41).

$$
C(s)=k_{p}+\frac{k_{i}}{s}
$$

Using (38), we calculate the system transfer function $H(s)$ and we do the dq-axis current control loop in Fig. 7. Where, $s$ is the Laplace operator.

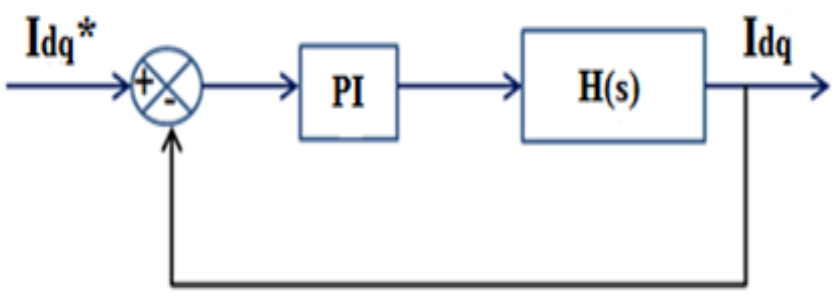

Fig. 7. $\boldsymbol{d q}$-axis current control loop [7].
The system open loop transfer function is given in (42).

$$
G O(s)=C(s) \cdot H(s)=\frac{k_{p}+\frac{k_{i}}{s}}{L s+R}
$$

The closed loop transfer function is given in (43).

$$
\mathrm{GF}(s)=\frac{G O(s)}{1+G O(s)}=\frac{V_{D C}\left(k_{p} s+k_{i}\right) / L}{s^{2}+\left(\frac{R+k_{p}}{L}\right) s+\frac{k_{i}}{L}}
$$

\section{Calculation of the PI Parameters $\left(k_{p}, k_{i}\right)$}

The denominator of a second order system is giving in (44).

$$
s^{2}+2 z \omega_{i} s+\omega_{i}^{2}
$$

By identifying the denominator of (43) with (44), the parameters of the PI controller are obtained in (45) [7].

$$
\left\{\begin{array}{l}
k_{p}=2 z \omega_{i} L-R \\
k_{i}=L \omega_{i}^{2}
\end{array}\right.
$$

Where $z$ is the damping factor, $\omega_{i}$ is the filter pulsation $\left(\omega_{i}=\frac{1}{t_{i}}\right.$; with $t_{i}$ is the time constant). We consider $z=0.707$ eliminating the system oscillations.

Using Table 2, we obtain: $L=2.6 \mathrm{mH}, R=1.7 \Omega$, $t_{i}=\frac{L}{R}=1.5 \mathrm{~ms}$ and $\omega_{i}=648 \mathrm{rad}$.

So the PI controller parameters for the external loop are: $k_{p}=0.708$ and $k_{i}=1.107 \cdot 10^{3}$.

\section{Control of the Cell Currents (Internal Loop)}

The internal loop combined with the Pulse Width Modulation (PWM) bloc is shown in Fig. 8.

Where: $i_{i x}$ are the cell currents whereas $i_{i x}{ }^{*}$ are the references cell currents obtained after inverse Park transform of $d q$ - axis; $i=1,2 . . q$ is the cell identifier where $q$ is the number of cells; $\mathrm{V}_{\mathrm{y}}{ }^{*}$ is the array of reference voltages obtained after inverse Park transform before balancing; $y=1,2,3$ is the phase number before balancing $A n d V_{x}{ }^{*}$ is the array of reference voltages obtained after balancing operation $(x=$ $a, b, c$ is the phase name).

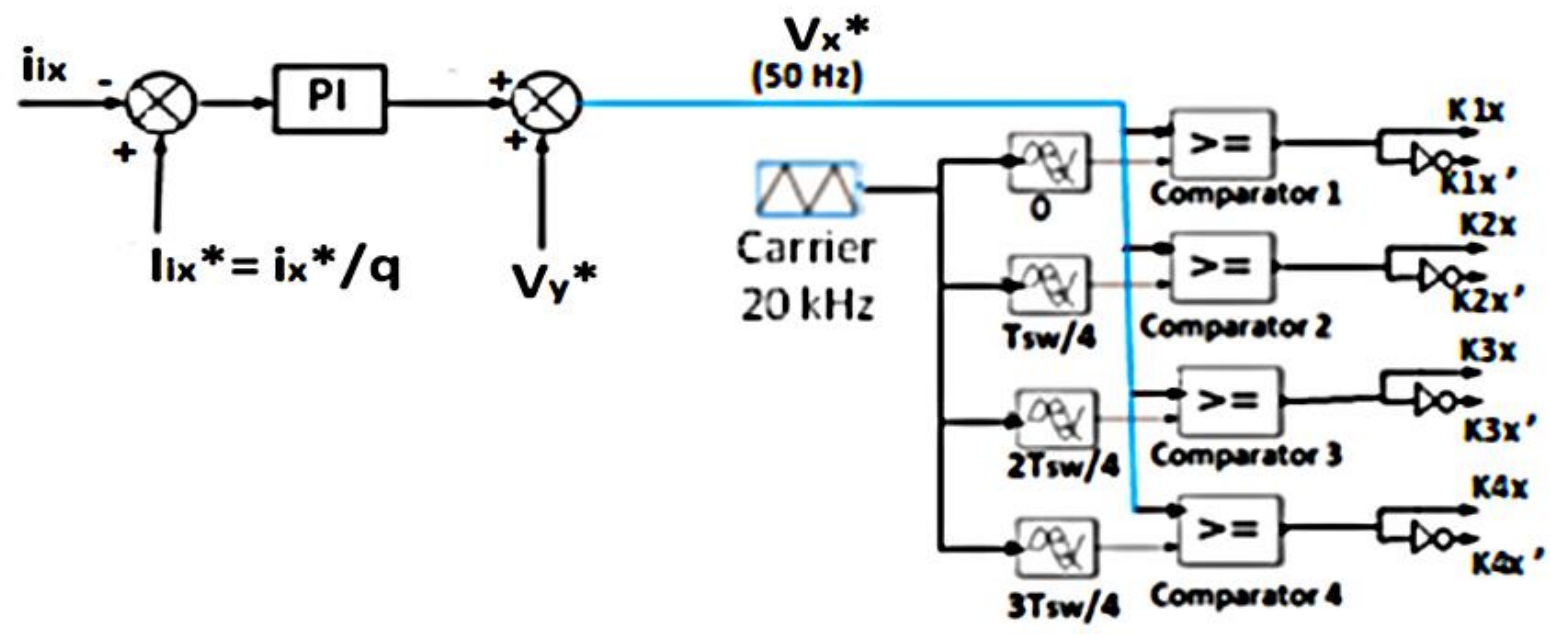

Fig. 8. Internal Loop and $\boldsymbol{P W M}$ bloc. 
Our control system can be assimilated to a cascade control with an external loop to control the output current and an internal loop for the cell currents control. In the case of the two cascaded loops, the internal loop must be faster than the external loop [13]. To calculate the PI parameters of the cell currents (internal loop), we have chosen a bandwidth smaller than ten times the switching frequency. We chose a value of $f_{i}=2 \mathrm{kHz}$ for this frequency. Moreover, the damping factor chosen is $z=0.707$ which gives a fast response without overshooting [14]. The total inductance and resistance values are $L=2.6 \mathrm{mH}$ and $=1.7 \Omega$. For these parameters and with the defined bandwidth and damping factor values, we calculate the values of the PI parameters ( $k_{p 1}$ and $k_{i 1}$ ) by using (45) [14]. So (45) becomes (46).

$$
\left\{\begin{array}{l}
k_{p 1}=2 z \omega_{i 1} L-R \\
k_{i 1}=L \omega_{i 1}{ }^{2}
\end{array}\right.
$$

Were $\omega_{i 1}=2 \pi f_{i}$ is the pulsation corresponding to the bandwidth; $k_{p 1}$ and $k_{i 1}$ are the $P I$ parameters for the internal loop. We obtain $k_{p 1}=45.22$ and $k_{i 1}=4.17 \cdot 10^{5}$.

\section{SIMULATION RESULTS AND DISCUSSION}

The simulation is done using Matlab Simulink and SimPower Systems by considering the specifications given in Table 2.

So in order to test the developed control, we set

$Q^{*}=0$ and $P^{*}$ is varied on time $(t)$ as follows:

- for $t \in\left[\begin{array}{ll}0 & 1\end{array}\right] \mathrm{s}, P^{*}=5.2 \mathrm{~kW}$

- for $t \in\left[\begin{array}{ll}1 & 2\end{array}\right] \mathrm{s}, P^{*}=3.2 \mathrm{~kW}$

- and for $t \in\left[\begin{array}{ll}2 & 3\end{array}\right] \mathrm{s}, P^{*}=5.2 \mathrm{~kW}$.
Where $Q^{*}$ and $P^{*}$ are the reactive and active power references respectively.

Some simulation results are shown in Fig. 8 to 14 . We can see in Fig. 8 that the current waveform varies according to $P^{*}$. This is normal because by varying $P^{*}$ we indirectly vary the current $\left(i_{a b c}{ }^{*}\right)$ (This variation is also noticeable in Fig. 9 and 10). Thus, the developed control tracks the references and can be validated.

Fig. 9 and 10 show the waveforms of the cell currents without and with balancing respectively. The balancing of cell currents is necessary to evenly distribute the output current between the different cells in order to increase the reliability of the system [4], [5], [14]. Note that the output current is equal to $q$ times the cell current $\left(i_{x}=q \cdot i_{i x}\right)$.

Fig. 11 shows the waveform of the three-phase grid voltage where we can see that the voltage is sinusoidal and smooth. Therefore, our system injects current into the grid without disturbing it.

To check the condition of current frequency and grid frequency matching, we need a Phase Locked Loop (PLL ) to synchronize our system with the grid [6]. Fig. 12 shows the superposition of the injected current into the grid of the phase $a$, on the simple grid voltage curve of the same phase. We can see that the current $\left(i_{a}\right)$ and the grid voltage $\left(V_{a}\right)$ are in phase and have the same frequency $(50 \mathrm{~Hz})$.

Fig. 13 shows the current and voltage Total Harmonic Distortion (THD). The THD of the current is equal to $2.82 \%$ (cf. Fig. 13(a)) whereas the THD of the voltage is equal to $3.56 \%$ (cf. Fig. 13(b)). Both THD respect the IEE1547 standard which requires $T H D$ to be smaller than $5 \%$ for the first 50 harmonics [10].

\section{(a): The three-phase output current (ix) vs time}

\section{(b): Zoom on ix vs time}

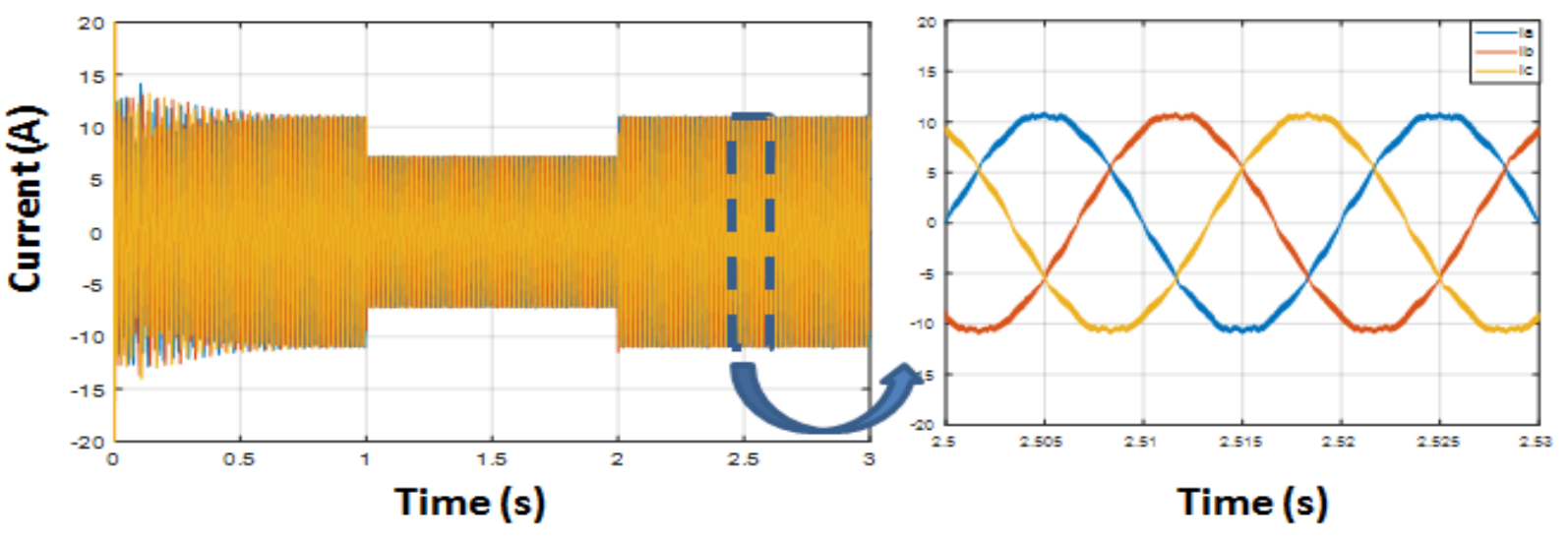

Fig. 9. Three phase output current $\left(\boldsymbol{i}_{\boldsymbol{a b c}}\right)$. 


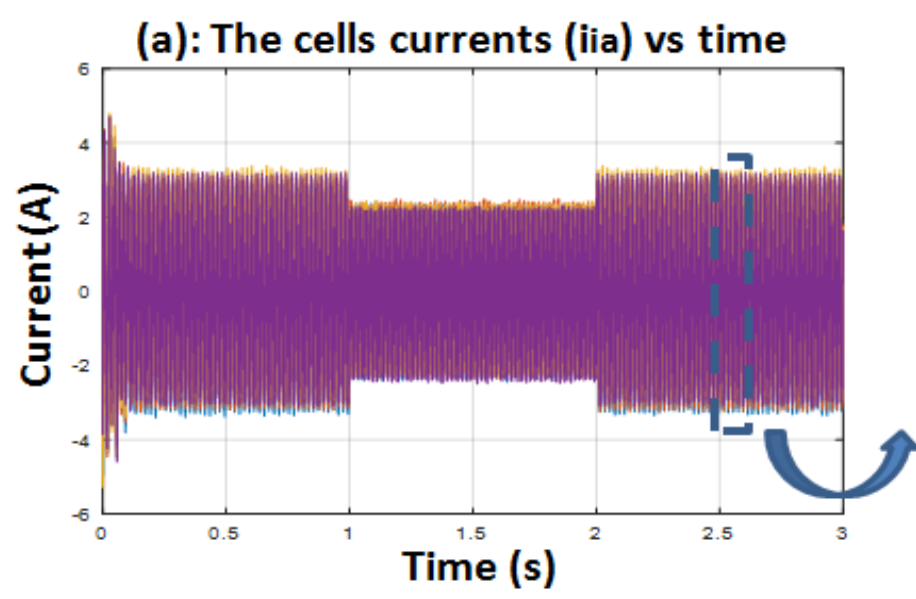

(b): Zoom on the iia vs time

Fig. 10. Unbalanced cells currents $\left(\boldsymbol{i}_{i \boldsymbol{i}}\right)$ for one phase.

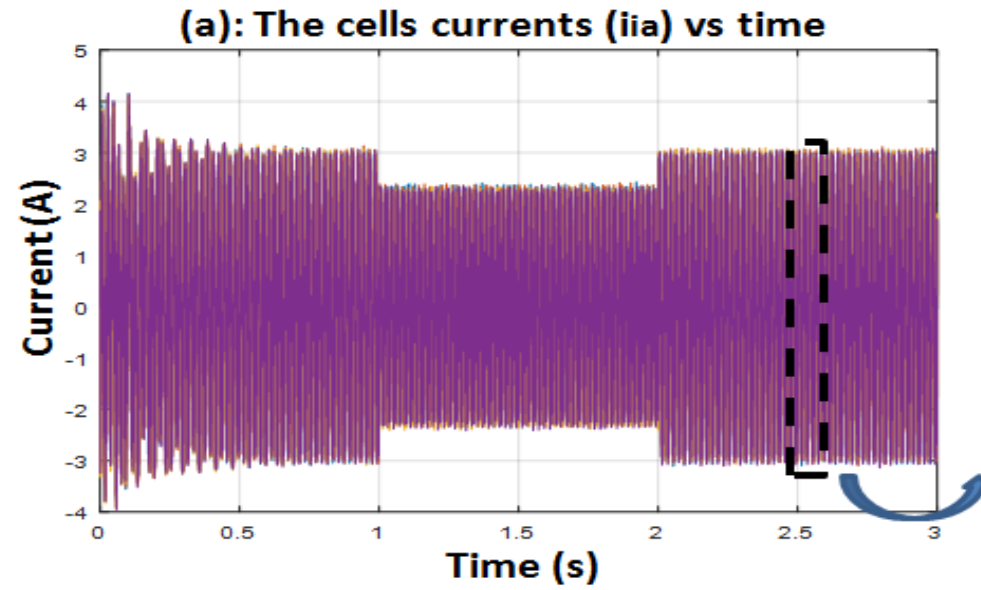

(b): Zoom on the iia vs time

Fig. 11. Balanced cells currents $\left(i_{i a}\right)$ for one phase.

(a): Waveforms of the grid voltage (Vabc) vs time

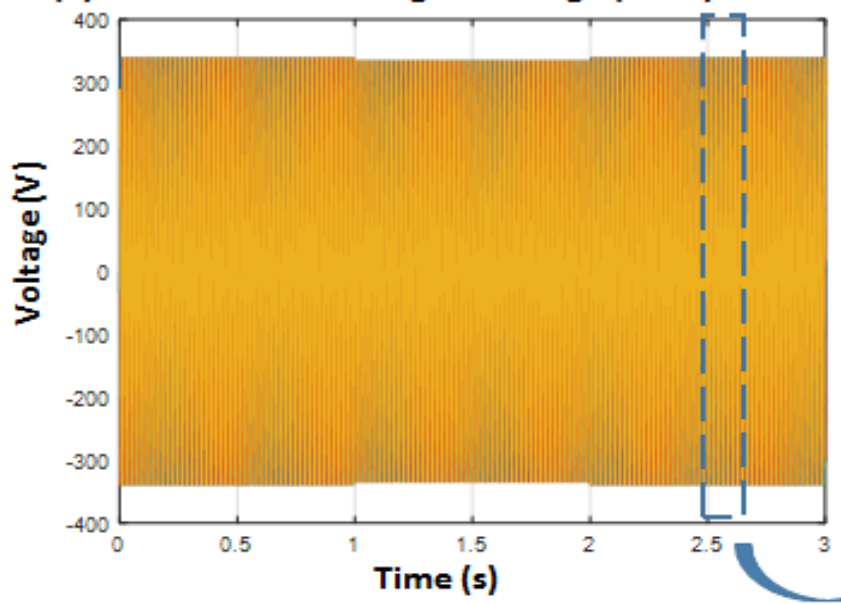

(b): Zoom on Vabc vs time

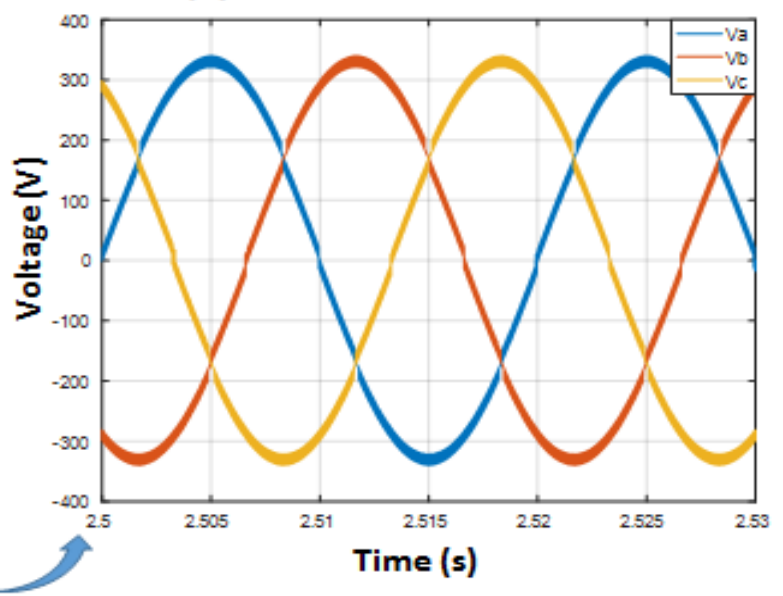

Fig. 12. Waveform of the inerter output voltage. 


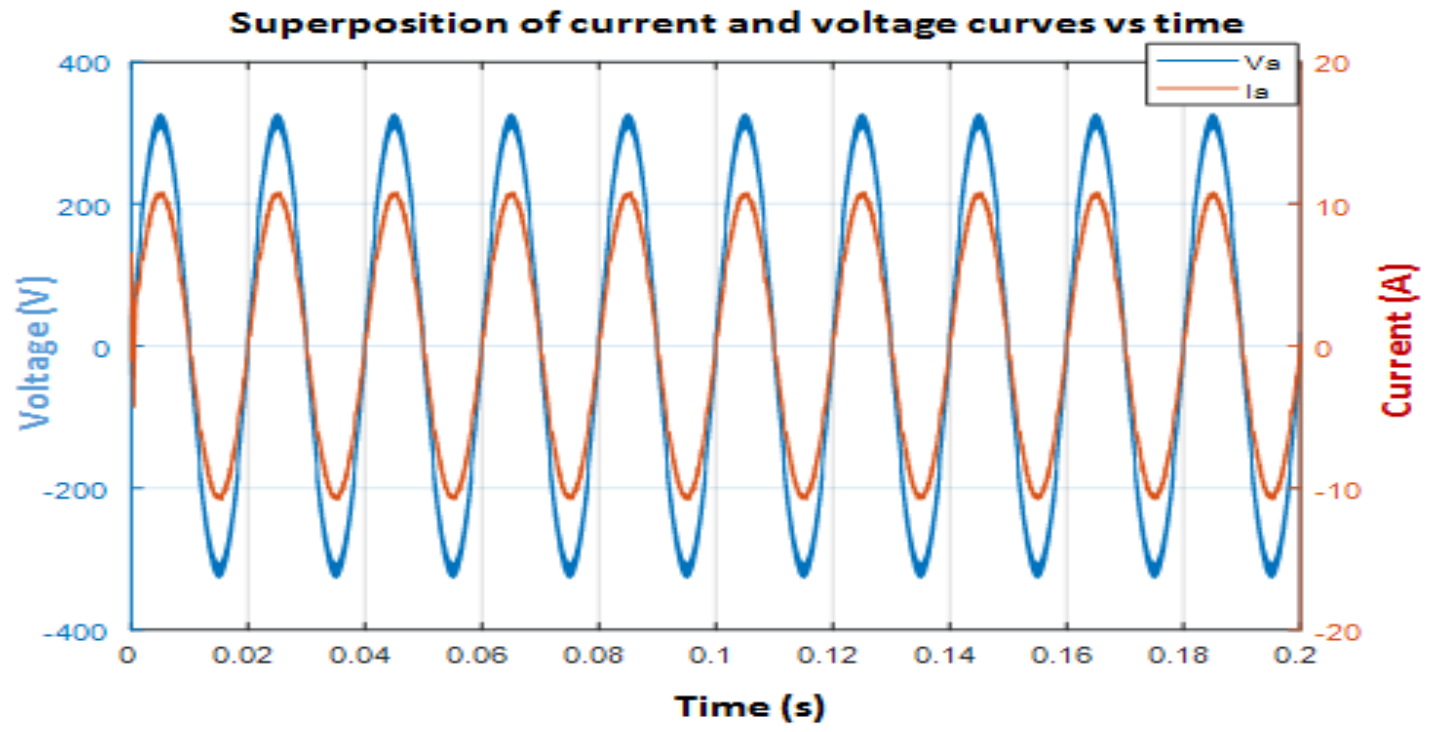

Fig. 13. PLL simulation result.

(a): Total Harmonic Distorsion (THD ) of output curent

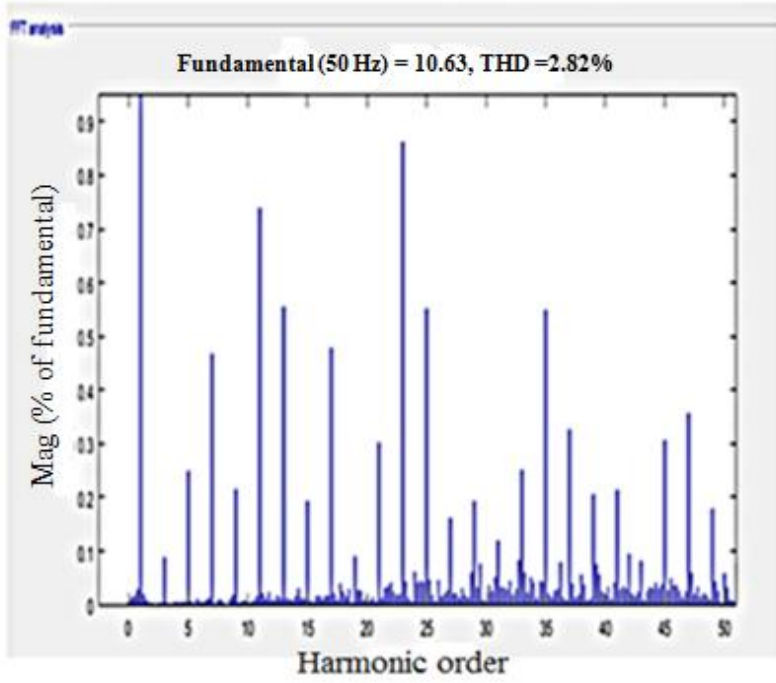

(b): Total Harmonic Distorsion (THD) of output voltage

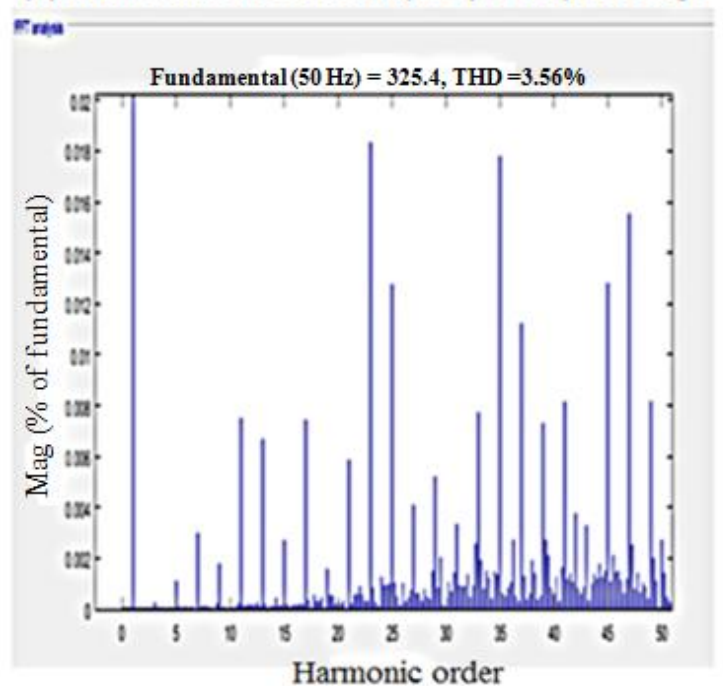

Fig. 14. Frequency analysis curves.

\section{CONCLUSION}

The sizing of passive elements and simulation results showed the value of the $F L I$ converter. The strengths of this inverter are the quality of the waveforms (see Fig. 3), the reliability of the system obtained by using several cells and the reduction of the output filter volume. The developed balanced $P Q$ - control allowed to follow the instructions while balancing the currents flowing through the switching cells of the FLI. The balancing of cells currents is very important to increase the reliability of the system. The interleaved $L$ - filter has been sized to obtain a current THD equal to $2.82 \%$ and a voltage THD equal to $3.56 \%$.

However, the disadvantage of the proposed architecture is the number of semiconductors used to make the FLI.
Fortunately, this disadvantage can be mitigated by the reliability of the system and the low price of the semiconductors [7].

In the future, it would be interesting to take into account the impact of the neighbor's consumption on our system.

\section{REFERENCES}

[1] A. Reznik, M. S.-D. (2012). LCL Filter Design and Performance Analysis for Grid Interconnected Systems . Power Electronics and Machines in Wind Application (PEMWA), IEEE , 1-7.

[2] Xu Renzhong, X. L. (2013). Design and Research on the LCL Filter in Three-Phase PV Grid-Connected Inverters. International Journal of Computer and Electrical Engineering, Vol. 5, No. 3.

[3] BAYOUMI, E. H. (2015). Three-phase LCL-filter for Grid-connected Inverter Using Cooperative Bacteria Foraging Optimization . Wesas transactions on Systemes and Control, Volume 10. 
[4] Fabien, A. (2011). Onduleur multicellulaire paralèlle à ICT: commande équilibrante, analyse,modélisation, et optimisation des performances

[5] CEM. PhD thesis, ENS-CACHAN, Cachan, France.

[6] Guepratte, K. (2011). Onduleur triphasé à structure innovante pour application aéronautique. $\mathrm{PhD}$ thesis, Université de Grenoble.

[7] Nguyen, V. L. (2015). Couplage des systemes photovoltaiques et des vehicules electriques au reseau Problemes et solutions. PhD thesis Université de Grenoble.

[8] Mahamat, C., Petit, M., Marouani, R., Gautier, C., Mami, A., \& Costa, F. Decoupled PQ control applied to a multicellular parallel inverter for grid-connected photovoltaic system.: IEEE Conference Publications: 2016 17th International Conference on Sciences and Techniques of Automatic Control and Computer Engineering (STA). Sousse, Tunisia.

[9] SNE. (2015). FORMATION SUR LE RESEAU ELECTRIQUE DE LA SNE. N'djamena,Tchad: Document technique de la Societé Nationale d'Electricité (SNE).

[10] France Transo, S. E. (2010). transformateurs TPC de distribution HTA/BT. Minera, distribution publique : Transformer Datasheet.

[11] Standard 1547, I. (2003). IEEE Standard for Interconnecting Distributed Resources with Electric Power Systems.

[12] Houssem CHAOUALI (*), H. O. (2017). Energy Management Strategy of a PV/Fuel Cell/Supercapacitor Hybrid Source Feeding an off-Grid Pumping Station. UR-LAPER, UR17ES11, Faculty of Sciences of Tunis,University of Tunis El Manar, 2092 Tunis, Tunisia: (IJACSA) International Journal of Advanced Computer Science and Applications.
[13] Soomaiya Hamid, N. Z. (2017). ReCSDN: Resilient Controller for Software Defined Networks. Systems Research Laboratory, Department of Computer Science, FAST National University of Computer and Emerging Sciences,Karachi, Pakistan: (IJACSA) International Journal of Advanced Computer Science and Applications.

[14] Jean-Paul Ferrieux et François Forest (1999): Alimentation à découpage Convertisseurs à résonance, Principes-composant-modélisation. 3rd edition DUNOD, Paris.

[15] Michel Beltramini. Contribution à l'optimisation de l'ensemble convertisseur / filltres de sortie vis à vis des contraintes CEM avion. Energie électrique. $\mathrm{PhD}$ thesis, Institut National Polytechnique de Toulouse - INPT, 2011.

[16] Marco Liserre, F. B. (2005). Design and Control of an LCL-Filter-Based Three-Phase Active Rectifier. IEEE TRANSACTIONS ON INDUSTRY

[17] APPLICATIONS, VOL. 41, NO. 5, SEPTEMBER/OCTOBER 2005.

[18] Houssem CHAOUALI (*), H. O. (2017). Improving the Control Strategy of a Standalone PV Pumping System by Fuzzy Logic Technique. (IJACSA) International Journal of Advanced Computer Science and Applications Vol. 8, No. 3, 2017.

[19] S. V. Araujo, A. E. (2007). LCL Filter design for grid-connected NPC inverters in offshore wind turbines. The 7th International Conference on

[20] Tsai-Fu Wu, S. M.-C.-W. An Improved Resonant Frequency Based Systematic LCL Filter Design Method for Grid-Connected Inverter . DOI 10.1109/TIE.2017.2682004, IEEE Transactions on Industrial Electronics. 